\title{
Autologous Platelet-Rich Fibrin (PRF) as an Adjunct in the Management of Osteoradionecrosis and Medication-Related Osteonecrosis of Jaws. Case Series in A Single Centre
}

\author{
Benjie Law ${ }^{1}\left(\mathbb{D}\right.$, Hui Yuh Soh ${ }^{2}$, Syed Nabil ${ }^{2}\left(\mathbb{D}\right.$, Rama Krsna Rajandram ${ }^{2}$, Abd Jabar Nazimi ${ }^{2}(\mathbb{D}$ \\ and Roszalina Ramli $2, *$ (D) \\ 1 Oral and Maxillofacial Surgery Unit, Department of Surgery, Hospital Canselor Tuanku Muhriz (HCTM), \\ Universiti Kebangsaan Malaysia, Kuala Lumpur 56000, Malaysia; benjielaw@gmail.com \\ 2 Department of Oral and Maxillofacial Surgery, Faculty of Dentistry, Universiti Kebangsaan Malaysia, \\ Jalan Raja Muda Aziz, Kuala Lumpur 50300, Malaysia; sohhuiyuh@ukm.edu.my (H.Y.S.); \\ syednabil@ppukm.ukm.edu.my (S.N.); ramakrsna@ppukm.ukm.edu.my (R.K.R.); \\ mohdnazimi@ukm.edu.my (A.J.N.) \\ * Correspondence: roszalina@ppukm.ukm.edu.my; Tel.: +60-19-310-1918
}

Citation: Law, B.; Soh, H.Y.; Nabil, S.; Rajandram, R.K.; Nazimi, A.J.; Ramli, R. Autologous Platelet-Rich Fibrin (PRF) as an Adjunct in the Management of Osteoradionecrosis and Medication-Related Osteonecrosis of Jaws. Case Series in A Single Centre. Appl. Sci. 2021, 11, 3365. https:// doi.org/10.3390/app11083365

Academic Editors: Vanessa Nicolin, Claudio Stacchi and Bruno Chrcanovic

Received: 30 January 2021

Accepted: 5 April 2021

Published: 8 April 2021

Publisher's Note: MDPI stays neutral with regard to jurisdictional claims in published maps and institutional affiliations.

Copyright: (c) 2021 by the authors. Licensee MDPI, Basel, Switzerland. This article is an open access article distributed under the terms and conditions of the Creative Commons Attribution (CC BY) license (https:// creativecommons.org/licenses/by/ $4.0 /)$.
Featured Application: Enhancement of healing in osteoradionecrosis and medication-related osteonecrosis of jaws.

Abstract: Osteoradionecrosis (ORN) of the jaws and medication-related osteonecrosis of the jaws (MRONJ) are uncommon but serious diseases affecting the oral and maxillofacial region with clinically similar appearance but distinct pathophysiology. Management of ORN and MRONJ is inherently challenging and the treatment outcomes are unpredictable. The use of autologous platelet concentrates (APCs) to promote hard and soft tissue healing is well described in the literature, and the efficacy of leucocyte and platelet-rich fibrin (L-PRF) has been well documented in a number of clinical studies. The aim of this study was to present our treatment strategy and the outcomes of incorporating L-PRF as a surgical adjunct in management of ORN and MRONJ in our centre. Methods: eight cases of ORN and MRONJ were treated with a combination of sequestrectomy and L-PRF as a surgical adjunct. Results: the overall success was $87.5 \%$. Using L-PRF as an adjunct, we were able to predictably manage ORN and MRONJ without causing significant morbidity. Conclusion: our experience shows that L-PRF may be used as a valuable and cost-effective adjunct to surgical management of ORN and MRONJ. However, due to a limited number of patients, and a short period of review, the true effectiveness of the method is yet to be demonstrated in a longer follow-up study including a greater number of patients, besides the inclusion of a control group.

Keywords: osteoradionecrosis; ORN; jaw; bisphosphonate; MRONJ; osteonecrosis; L-PRF; plateletrich fibrin; PRF; PRP

\section{Introduction}

Historically, fibrin adhesives were used in oral and maxillofacial surgery for hemostasis after dental extraction in patients with clotting disorders, neural anastomoses, and skin grafts placement, in combination with the use of bone grafts for alveolar ridge augmentation and filling of bony cavities following cyst removal [1]. In 1994, Tayapongsak published the first report on the use of autologous non-transfusional hemocomponents in oral and maxillofacial surgery [2]. An autologous fibrin adhesive (AFA) was added to a cancellous bone graft during mandibular reconstruction, and the results demonstrated earlier radiographic bone consolidation compared to bone grafts without AFA [2].

Platelet concentrate refers to an autologous concentration of human platelets obtained by centrifuging blood. This results in a high concentration of several protein growth factors secreted actively by platelets. The first use of autologous platelet concentrates 
(platelet-rich plasma (PRP)) in maxillofacial surgery was introduced by Marx et al. in 1998, in which at least three growth factors (platelet-derived growth factor (PDGF), transforming growth factor beta 1 (TGF- $\beta 1$ ), and transforming growth factor beta 2 (TGF- $\beta 2$ ) were identified in PRP. Healing of bone grafts with the addition of these growth factors produce a quantifiably enhanced result, evidenced by higher radiographic maturation rate and greater bone density shown by histomorphometric analysis [3]. However, up to the present time, controversy surrounds the efficacy of PRP and its true role in osteoinduction [4-6].

The PRP products are subdivided according to leukocyte and fibrin content as follows: pure PRP (P-PRP), also known as plasma rich in growth factors (PRGF) or leukocyte-poor PRP, such as Cell Separator PRP [7] or Anitua' PRGF [8]; leukocyte- and platelet-rich plasma (L-PRP), such as PCCS [9] or Ace PRP [10]; pure platelet-rich fibrin (P-PRF), such as Fibrinet PRFM [11]; and leukocyte- and platelet-rich fibrin (L-PRF), such as Choukroun's PRF [12]. The details of each platelet concentrate are described elsewhere [7-12].

Leucocyte- and platelet-rich fibrin (L-PRF) has been considered as the second generation of platelet concentrate, and it was developed by Choukroun et al. in 2001 [12]. Unlike PRP, L-PRF does not dissolve and disintegrate quickly due to the elimination of the anticoagulants or gelling agents while centrifuging. In the absence of anticoagulants, platelet activation and fibrin polymerization are triggered immediately. The L-PRF membrane has been shown to slowly release a significant amount of three main growth factors, namely, the TGF $\beta 1$, platelet-derived growth factor AB (PDGF-AB), vascular endothelial growth factor (VEGF), and an important coagulation matricellular glycoprotein (thrombospondin-1, TSP-1) during at least the first seven days [13] up to 28 days [5].

Intricate interaction between cellular and molecular pathways during wound healing progresses to the early and late inflammation phases, proliferation and migration of cells, angiogenesis, granulation tissue formation, and (finally) matrix formation and remodeling following tissue injury [14]; the role of each growth factor has been described elsewhere [15-17].

Necrosis of the jawbones is dreadful, and debilitating complications that may develop following radiotherapy in the head and neck region, resulting in osteoradionecrosis (ORN), or from the therapeutic use of antiresorptive and antiangiogenic medications, resulting in medication-related osteonecrosis of the jaw (MRONJ). There is no universally accepted consensus for the best treatment of these lesions as treatment outcomes are unpredictable.

\subsection{Osteoradionecrosis}

Different terminologies and definitions have been used to describe osteoradionecrosis (ORN) [13]. The most widely used definition is based on clinical presentation and observation: irradiated bone becomes devitalized and exposed through the overlying skin or mucosa without healing for three months, without recurrence of tumor [18]. The incidence of ORN in the head and neck-irradiated population was estimated to be 4.74$37.5 \%$ [19]. The contemporary understanding of the pathophysiology of ORN is based on the radiation-induced fibrosis theory introduced by Delanian in 2004 [20].

In general, ORN is managed based on clinical staging: early stages may respond to conservative treatments, while advanced cases often require aggressive resection and reconstruction with microvascular flap. Both conservative and surgical approaches have been used with varying degree of success. Conventional conservative treatment of ORN mainly consists of the use of antibiotic therapy, surgical debridement, hyperbaric oxygen (HBO), and antifibrotic medications (pentoxifylline, tocopherol) [20].

\subsection{Medication-Related Osteonecrosis the Jaw (MRONJ)}

In 2003, Marx reported a series of 36 patients presenting with painful bone exposure in the maxilla or mandible that were unresponsive to medical or surgical interventions. He then termed this clinical presentation as bisphosphonates-related osteonecrosis of the jaws (BRONJ) as all of these patients had receive intravenous bisphosphonates (Pamidronate (Aredia) or Zolderonate (Zometa) for the treatment of hypercalcemia secondary to multiple myeloma, metastatic breast carcinoma, and osteoporosis [21]. 
In 2014, the term "medication-related osteonecrosis of the jaw" (MRONJ) was introduced by American Association of Oral and Maxillofacial Surgeons (AAOMS) as it was proven that osteonecrosis of the jaws was not limited to the use of bisphosphonates (BP) alone [22]. It may also develop in patients on antiresorptive and antiangiogenic medications such as denosumab and bevacizumab. These drugs are often used for the treatment of malignancy with bone metastasis or metabolic bone disease, primarily osteoporosis.

The incidence of MRONJ in relation to denosumab was $1.8 \%$ versus zoledronate $1.3 \%$ in underlying malignancy and multiple myeloma [23], between $0.3 \%$ and $0.4 \%$ with bevacizumab [24], and 16\% among patients who received combined therapy of bisphosphonates and antiangiogenesis [25].

Based on the AAOMS 2014 position paper, MRONJ is defined as [22]

(1) Exposed bone or bone that can probed through an intraoral or extraoral fistula in the maxillofacial region that persisted for longer than 8 weeks;

(2) Current or previous treatment with antiresorptive or antiangiogenic agents;

(3) No history of radiation therapy to the jaws or obvious metastatic disease to the jaws.

The incidence of MRONJ was shown to be as high as $18.3 \%$ [26].

The exact pathophysiology of MRONJ is yet to be fully understood. Much of the current understanding on the pathophysiology is based on experimental findings in animal studies and their appraisal in the context of the human condition [27]. Various hypotheses have been discussed in the literature, including bone-remodeling inhibition, lack of immune resiliency, soft tissue toxicity, inflammation or infection, and angiogenesis inhibition [28].

Allegra et al. (2019) hypothesized that there is a possibility that antiresorptive and anti-angiogenetic drugs share a common pathogenetic mechanism. These drugs inhibit angiogenesis by interfering with endothelial cell proliferation and survival, leading to loss of blood vessels and avascular necrosis [29].

To date, no single treatment protocol has been proven to manage MRONJ with predictable outcomes [30]. Treatment strategies are guided by clinical staging ranging from conservative measures such as antimicrobial therapy and $0.12 \%$ chlorhexidine mouthwash during the initial stages to surgical debridement in advanced stages. Different therapeutic approaches have been used with variable success rate, including ozone therapy, hyperbaric oxygen therapy, teriparatide laser, pentoxifylline, and tocopherol, all of which aim to improve healing [30-32].

In this paper, we aim to present our treatment strategy and outcomes of incorporating the use of L-PRF as a surgical adjunct in treatment of ORN and MRONJ.

\section{Materials and Methods}

\subsection{Ethical Approval}

This study was approved by the Universiti Kebangsaan Malaysia Research Ethics Committee (UKM PPI/111/8/JEP-2020-738).

\subsection{Patient Selection}

This is a retrospective analysis of ORN and MRONJ cases treated with surgical debridement and the use of L-PRF as an adjunct. The operative records of patients treated in Oral and Maxillofacial Surgery Unit, Universiti Kebangsaan Malaysia Medical Centre from January 2016 to December 2020 were reviewed retrospectively to identify all ORN and MRONJ cases treated with surgical debridement with the use of L-PRF as adjunct.

The patients' demographic details and medical history were retrieved and recorded. Details of the treatment procedure and outcomes were also retrieved. The patients were diagnosed with ORN or MRONJ based on history, clinical and radiographic examination.

Generally, for all patients, an orthopantomogram or a cone beam computed tomography $(\mathrm{CBCT})$ was performed before surgery. One patient had a CT scan pre-operatively (Figure 1). 


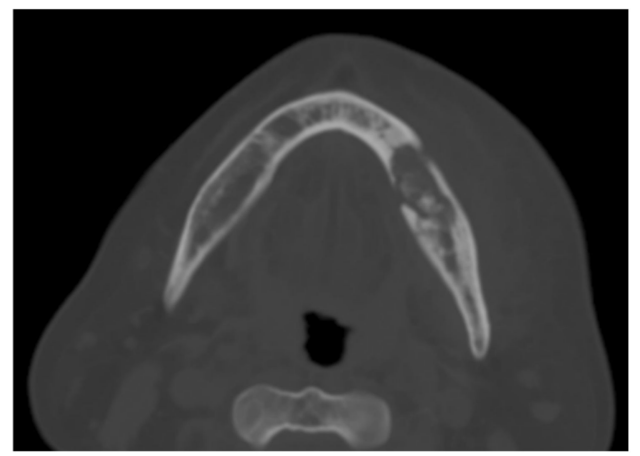

Figure 1. Pre-operative computed tomography (CT) scan showing medication-related osteonecrosis of the jaws (MRONJ) of her left mandible (36-38 area).

ORN was diagnosed if there was bone exposure that lasted for more than three months with signs of bone necrosis radiographically. ORN was staged based on Notani Classification [33], while MRONJ was staged according to the classification by Ruggiero et al. 2014 [22].

\subsection{Surgical Procedure}

All patients received surgical therapy consisting of sequestrectomy with the use of PRF as an adjunct.

Surgical debridement and sequestrectomy was performed using aseptic techniques under local or general anesthesia (depending on the extent of the disease). Access to the diseased sites (ORN or MRONJ) was achieved by raising a full thickness mucoperiosteal flap to fully expose the necrotic bone area. The necrotic bone is usually white or yellowish in color with absence of bleeding. It may be firmly attached to the basal bone but is more commonly loosely attached. The surface maybe smooth or irregular.

The mobile segments of bony sequestrum were removed, and peripheral ostectomy was performed with a round bur and constant saline irrigation until bleeding was observed from the underlying bone. Teeth with poor prognosis adjacent to the diseased sites were removed (Figure 2).

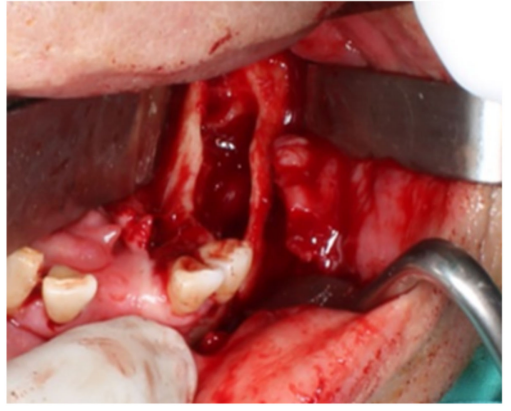

a

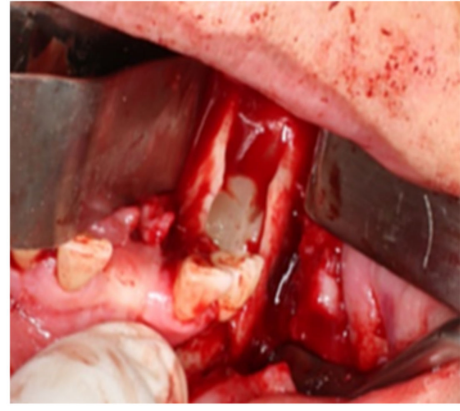

b

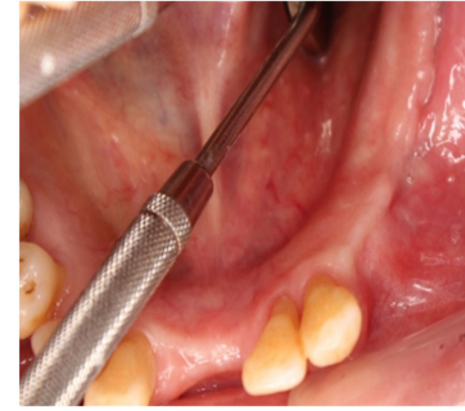

C

Figure 2. (a) Patient \#8: Bone defect exposed after debridement, curettage, and peripheral ostectomy; (b) the platelet-rich fibrin (PRF) clot placed into the bony defect; (c) healing after 2 months.

\subsection{PRF Preparation}

The PRF was processed according to the protocol described by Choukron et al. [7]. The patient's blood samples were taken prior to the surgery using aseptic techniques in sterile vacutainer tubes without anticoagulant. We took $20-50 \mathrm{~mL}$ of blood from the patients depending on the size of the defects.

Immediately after the blood draw, the tubes were centrifugated at $1300 \mathrm{rpm}$ (about $200 \mathrm{~g}$ ) for $10 \mathrm{~min}$ in a laboratory centrifuge (Process, Nice, France). 
Following completion of the centrifugation process, the platelet concentrate was removed from the tube with a tweezer and pressed into the dedicated PRF Box surgical kit (Process for PRF, Nice, France), to obtain a resistant fibrin membrane, known as the L-PRF clot (Figure 3). The membranes were then placed into the osseous defect before wound closure. The periosteum was released to ensure a tension-free wound closure using resorbable sutures.

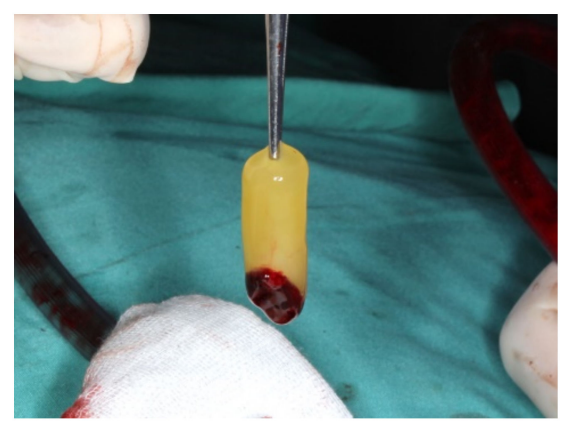

(a)

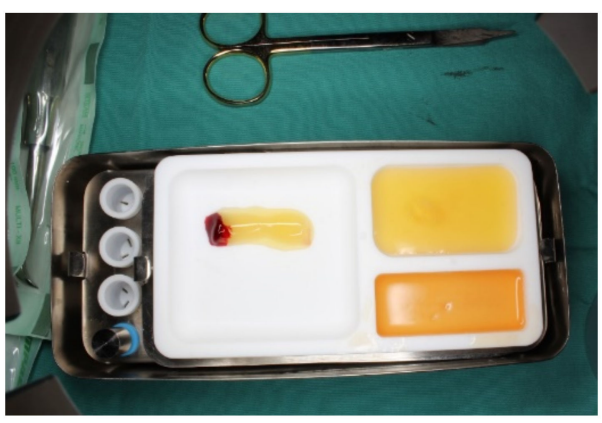

(b)

Figure 3. (a) The PRF clot removed from the tube with a tweezer; (b) the PRF clot pressed to obtain a resistant fibrin membrane.

All patients received post-operative instructions and a course of post-operative antibiotics. The patients who had surgical debridement under general anesthesia received a course of intravenous Augmentin $1.2 \mathrm{~g}$ (Amoxicillin $1000 \mathrm{mg}$ and Clavulanic Acid $200 \mathrm{mg}$ ) three times daily while being treated as in patient, and discharged with oral Augmentin (Amoxicillin $500 \mathrm{mg}$, Clavulanic Acid $125 \mathrm{mg}$ ) for a duration of five days up to two weeks. Patients who underwent surgical debridement under local anesthesia receive a course of oral Augmentin for a duration of seven days.

In addition to the above protocol, patient \#2 with advanced, refractory ORN of mandible received surgical debridement under general anesthesia, sequestrectomy, and obliteration of osseous defect with L-PRF and autogenous abdominal free-fat graft. Patient $\# 7$ and \#8 in the MRONJ group were given a course of Pentoxifylline (400 mg three times daily) and $\alpha$-tocopherol (1000 IU once daily) for 3 months post-operatively.

\subsection{Treatment Outcome and Follow Up}

Treatment outcome was categorized as "healed" or "failed". The outcome was described as healed if there was complete resolution of symptoms, absence of persistent infection, absence of persistent necrotic bony exposure three months after the treatment, and no signs of disease progression radiographically. Treatment outcome was described as "failed" if there was persistent infection, presence of persistent necrotic bony exposure, or recurrence within three months of treatment.

\section{Results}

A total of eight patients (four ORN and four MRONJ) were identified and included in this case series. The median age was 67.5 years (interquartile range, IQR: 8; range 54-78 years) (Table 1). Five were females and three were males (Table 1 ). Three oral and maxillofacial surgeons were involved in this case series.

Demographic details of the patient, including age, gender, medical history, details of the radiotherapy and bisphosphonate therapy, site(s) involved, history of tobacco use, procedures, treatment outcomes, and follow up status were summarized in Tables 2 and 3. 
Table 1. Characteristics of patients who had PRF following surgery in the jaw bones.

\begin{tabular}{cc}
\hline Characteristics & $n \mathbf{( \% )}$ \\
Gender & $3(37.5)$ \\
Male & $5(62.5)$ \\
Female & \\
Median age & \\
ORN vs. MRONJ & $4(50.0)$ \\
ORN & $4(50.0)$ \\
MRONJ & \\
Location of lesion in the jaw & $0(0.0)$ \\
Maxilla & $7(87.5)$ \\
Mandible & $1(12.5)$ \\
Maxilla \& mandible & $1(12.5)$ \\
History of smoking & $7(87.5)$ \\
Yes & $7(87.5)$ \\
No & $1(12.5)$ \\
\hline Healed &
\end{tabular}

Table 2. Clinical characteristics of patients with osteoradionecrosis (ORN) treated with PRF as adjunct.

\begin{tabular}{|c|c|c|c|c|c|c|c|c|c|c|c|c|}
\hline No & $\begin{array}{c}\text { Age } \\
\text { (y) }\end{array}$ & Sex & $\begin{array}{l}\text { Primary } \\
\text { Disease }\end{array}$ & $\begin{array}{c}\text { Details of } \\
\text { RT }\end{array}$ & Smoker & MH & Stage & Max/Mand & Site & Procedure & $\begin{array}{l}\text { Follow- } \\
\text { Up }\end{array}$ & Outcome \\
\hline 1 & 67 & M & $\begin{array}{l}\text { Adenoid } \\
\text { cystic } \\
\text { carcinoma } \\
\text { left parotid } \\
\text { gland }\end{array}$ & $\begin{array}{c}\text { CCRT 33\# } \\
\text { (Cisplatin) } \\
\text { EBRT 5\# }\end{array}$ & No & $\begin{array}{l}\text { BPH, } \\
\text { ED }\end{array}$ & 1 & Mand & 36,37 & $\begin{array}{c}\text { Multiple } \\
\text { extraction of 36, } \\
37 \text { with PRF } \\
\text { application and } \\
\text { PC }\end{array}$ & 3 years & Healed \\
\hline 2 & 64 & M & $\begin{array}{l}\text { SCC right } \\
\text { lateral } \\
\text { border of } \\
\text { tongue }\end{array}$ & $\begin{array}{l}\text { CCRT 35\# } \\
\text { (Cisplatin) }\end{array}$ & Yes & $\begin{array}{l}\text { AF, } \\
\text { COPD, } \\
\text { IHD, } \\
\text { DLP }\end{array}$ & 2 & Mand & 41 to 43 & $\begin{array}{l}\text { Sequestrectomy, } \\
\text { autologous free } \\
\text { fat graft } \\
\text { transplant, PRF } \\
\text { application }\end{array}$ & 4 years & Healed \\
\hline 3 & 54 & M & $\begin{array}{l}\text { Nasopharyng } \\
\text { Carcinoma }\end{array}$ & $\begin{array}{c}\text { CCRT } \\
\text { (Cisplatin, } \\
\text { 60Gy, 30\#) }\end{array}$ & No & $\begin{array}{l}\text { HPT, } \\
\text { DLP }\end{array}$ & 1 & Mand & 34,44 & $\begin{array}{c}\text { Multiple } \\
\text { extraction, } \\
\text { sequestrectomy, } \\
\text { PRF application } \\
\text { and PC }\end{array}$ & $\begin{array}{c}3 \\
\text { months }\end{array}$ & Healed \\
\hline 4 & 66 & $\mathrm{~F}$ & $\begin{array}{c}\text { Right } \\
\text { tonsillar } \\
\text { carcinoma }\end{array}$ & $\begin{array}{c}\text { CCRT } \\
\text { (Cisplatin, } \\
\text { 60Gy,30\#) }\end{array}$ & No & $\mathrm{HPT}$ & 2 & $\begin{array}{l}\text { Max, } \\
\text { Mand }\end{array}$ & 16,47 & $\begin{array}{c}\text { Multiple } \\
\text { extraction, } \\
\text { sequestrectomy, } \\
\text { PRF application } \\
\text { and PC }\end{array}$ & 3 years & Healed \\
\hline
\end{tabular}

* ORN staging is based on Notani Classification [24].

In patients with ORN, radiotherapy was given as part of the management of head and neck cancer. All four patients received concurrent chemo-radiotherapy with a total radiation dose ranging from 60-66 Gy in 30-35 fractions. All the patients with ORN healed successfully, with one patient receiving four dental implants for prosthetic rehabilitation.

In patients with MRONJ, bisphosphonates were prescribed as a treatment for osteoporosis in two patients and as adjunct preventive osteoporotic treatment for rheumatoid arthritis in one patient. One patient received intravenous bisphosphonate (Zoledronate) for management of breast malignancy in prevention of osteoporosis. Out of four patients with MRONJ, three healed successfully, although case \#6 had wound dehiscence initially, but after re-suturing, the area managed to heal well. The failed case (patient \#5) was a patient with extensive MRONJ involving bilateral mandible who achieved partial resolution. There was a clinical improvement with a decrease in area of bone exposure, an improvement in symptoms, and a general improvement in quality of life. At three years follow up, $10 \mathrm{~mm}$ 
bony exposure was noted on the right mandible. Patient refused further treatment due to her underlying health condition.

Follow-ups ranged from 3 months to 4 years. The overall success rate was $87.5 \%$, and failure rate was $12.5 \%$.

Table 3. Clinical characteristics of patients with medication-related osteonecrosis of the jaws (MRONJ) treated with PRF as adjunct.

\begin{tabular}{|c|c|c|c|c|c|c|c|c|c|c|c|c|}
\hline No & $\underset{\text { (y) }}{\text { Age }}$ & Sex & $\begin{array}{l}\text { Primary } \\
\text { Disease }\end{array}$ & Details of BP & Smoker & MH & $\underset{+}{\text { Stage }}$ & Max/Mand & Site & Procedure & $\begin{array}{c}\text { Follow- } \\
\text { Up }\end{array}$ & Outcome \\
\hline 5 & 77 & $\mathrm{~F}$ & Osteoporosis & $\begin{array}{l}\text { Ibandronate } \\
\text { (IV) } 2 \text { months }\end{array}$ & No & $\begin{array}{l}\text { DM, } \\
\text { HPT, } \\
\text { CKD }\end{array}$ & 2 & Mand & 34 to 44 & $\begin{array}{c}\text { Sequestrectomy, } \\
\text { PRF application } \\
\text { and PC }\end{array}$ & 3 years & Failed \\
\hline 6 & 69 & $\mathrm{~F}$ & $\begin{array}{l}\text { Rheumatoid } \\
\text { arthritis }\end{array}$ & $\begin{array}{l}\text { Alendronate } \\
\text { (oral) } 15 \text { years }\end{array}$ & No & $\begin{array}{c}\text { HPT, } \\
\text { CS, } \\
\text { OA, } \\
\text { PF, } \\
\text { DLP }\end{array}$ & 2 & Mand & 33,34 & $\begin{array}{l}\text { Sequestrectomy, } \\
\text { extraction } 34, \\
\text { PRF application } \\
\text { and PC }\end{array}$ & 2 years & Healed \\
\hline $7 \ddagger$ & 78 & $\mathrm{~F}$ & $\begin{array}{l}\text { Left breast } \\
\text { carcinoma }\end{array}$ & $\begin{array}{l}\text { Zoledronate } \\
\text { (IV) } 3 \text { years }\end{array}$ & No & DLP & 2 & Mand & 36 & $\begin{array}{c}\text { Sequestrectomy, } \\
\text { PRF application } \\
\text { and PC }\end{array}$ & $\begin{array}{c}4 \\
\text { months }\end{array}$ & Healed \\
\hline $8 \ddagger$ & 68 & $\mathrm{~F}$ & Osteoporosis & $\begin{array}{l}\text { Alendronate } \\
\text { (oral) } 2 \text { years }\end{array}$ & No & $\begin{array}{l}\text { DM, } \\
\text { HPT, } \\
\text { DLP }\end{array}$ & 2 & Mand & 36 to 38 & $\begin{array}{c}\text { Sequestrectomy, } \\
\text { PRF application } \\
\text { and PC }\end{array}$ & $\begin{array}{c}3 \\
\text { months }\end{array}$ & Healed \\
\hline
\end{tabular}

${ }^{\dagger}$ MRONJ staging is based on American Association of Oral and Maxillofacial Surgeons (AAOMS) Classification [17]. ${ }^{\ddagger}$ Patient No.7 and 8 in the MRONJ group receive pentoxyfylline and tocopherol post-operatively. RT-Radiotherapy, BP-Bisphosphonates, MH-Medical History, Max-Maxilla, Mand-Mandible, PRF-Platelet-Rich Fibrin, PC—Primary Closure. CCRT—Concurrent chemoradiotherapy, EBRT-External Beam Radiotherapy, SCC - Squamous Cell Carcinoma, BPH—Benign Prostate Hyperplasia, ED-Erectile Dysfunction, COPD—Chronic Obstructive Pulmonary Disease, DM—Diabetes Mellitus, DLP—Dyslipidemia, HPT—Hypertension, CKD—Chronic Kidney Disease, CS-Cervical Spondylitis, OA-Osteoarthritis, PF-Pulmonary Fibrosis.

\section{Discussion}

In this series of patients, one patient (patient \#2) received autogenous free fat graft (AFFG) transplant combined with L-PRF for management of ORN. This patient was previously managed with multiple sessions of surgical debridement over a period of two years but failed to show any satisfactory healing. There was recurrent infection with suppuration at the ORN defect. AFFG was used to obliterate the osseous defect with PRF lining the recipient bed as there was inadequate soft tissue to cover the defect. The remaining cases in this series have adequate soft tissue to allow primary closure. In the MRONJ group, drug holiday was not advised in patients \#5 and \#6 due to the high fracture risk, while in patients \#7 and \#8, decision of treatment break for three months was made in view of low to moderate fracture risk. The administration of pentoxifylline and $\alpha$-tocopherol post-operatively in patients \#7 and \#8 for management of MRONJ was similar to previous report by Epstein et al. 2010 [31]. The medications were well tolerated, and no adverse effects were reported.

The use of autologous platelet concentrates in the management of both ORN and MRONJ has immense therapeutic potential. L-PRF, a second-generation APC, is preferred to PRP in the management of such lesions for a few reasons. Firstly, elimination of anticoagulants during its preparation ensures that it is strictly autologous with no additional chemicals. This reduces the possibility of any immunogenic reaction. Secondly, its improved formulation allows it to be used in either a liquid or solid form.

Three layers are formed after centrifugation: the red blood cell base layer, acellular plasma top layer, and a PRF clot in the middle. The L-PRF clot is a strong fibrin matrix with a complex three-dimensional architecture containing a dense concentrate of platelets and leucocytes, as well as a variety of growth factors and cytokines, including transforming growth factor beta 1 (TGF- $\beta 1$ ), platelet-derived growth factor (PDGF), vascular endothelial growth factor (VEGF), interleukin (IL)-1 $\beta$, IL-4, and IL-6 [34]. Thirdly, unlike PRP, L-PRF does not dissolve quickly after use, leading to an increased lifespan for cytokines. It also shows a substantial embedding of the growth factors of platelets and leucocytes into the 
more favorable architecture of the physiological fibrin matrix [35]. In-vitro culture studies $[36,37]$ and experiment comparing L-PRF and PRP gel show that the L-PRF membrane remains intact after seven days, therefore confirming that the fibrin architecture is stronger in the PRF subfamilies when compared to the PRP gel classes [38]. The extrinsic form of L-PRF as a solid dense fibrin membrane makes it a suitable biomaterial to be used as an adjunct to stimulate tissue healing and regeneration, by serving as a biological healing matrix while maintaining a slow, sustained release of growth factors and key adhesion proteins during the healing period. The ease of preparation, relatively inexpensive technique, and ability to produce high-quantity L-PRF clots simultaneously without the use of chemicals are the several advantages of L-PRF, making it a novel addition to the surgeon's arsenal in regeneration of hard and soft tissue defects.

Management of necrotic defects of jawbones (both ORN and MRONJ) is often challenging. This is due to the compromised host healing process and existing tissue destruction that cannot be reversed into regeneration. The concept of using platelet concentrates is aimed at enhancing the compromised natural healing biology of the host. The slow and sustained release of mitogenic growth factors (TGF $\beta 1$, PDGF-AB, and VEGF) and key adhesion proteins (TSP-1, fibronectin, and vitronectin) from L-PRF play an important role in re-orchestrating the molecular cascade of healing. The therapeutic advantage of L-PRF to promote tissue regeneration is derived through the ability to restore the natural healing process by stimulating the different pathways that ultimately lead to the activation of gene expression and the production of necessary proteins for healing [39].

The PRF clot has been shown to quickly stimulate tissue healing by significantly increasing the recruitment and proliferation of a variety of cells, including endothelial cells, gingival fibroblast, chondrocytes, and osteoblast, thereby heavily promoting tissue repair and angiogenesis at site of injury [40]. These processes are regulated by local concentration of cytokines and growth factors trapped within the fibrous scaffolding. The increase of leucocytes and macrophages in the microenvironment can offer additional antibacterial defense against potential pathogens and reduce the risk of bacterial infection. Additionally, macrophages have been shown to be key mediators in osseous healing both during modeling and remodeling [41].

The biological effects of PRF in bone regeneration was investigated and proven. In a study conducted by Wu et al. [42], PRF was found to increase human osteoblast attachment and proliferation by enhancing Akt phosphorylation pathway and simultaneously upregulating collagen-related protein production by increasing expression of heat shock protein 47 (HSP47) and lysyl oxidase (LOX) in human osteoblasts, resulting in increased production of a collagen matrix for bone regeneration.

PRF has superior potential in promoting bone regeneration as compared to PRP. The activation of thrombin during PRP preparation resulted in large, immediate release of growth factors for a short duration, and this release could be lost in the interstitium in vivo before the onset of osteoblasts ingrowth. It was found that $81 \%$ of total TGF- $\beta 1$ and similar levels of total PDGF-AB are released within the first day, with significantly decreased release on the $3 \mathrm{rd}, 7$ th, and 14 th day [5,43].

The first report on the use of platelet concentrate as a surgical adjunct in management of ORN was by Scala et al. in 2011 [44]. In this case, PRP was used, successful healing of a mandibular ORN was observed, and the beneficial effects of PRP on healing of ORN was described. However, results from a double blinded randomized controlled trial failed to show any benefit of PRP in the prevention of ORN [45].

There is a paucity of high-level evidence data in the therapeutic value of platelet concentrate as surgical adjunct in the management of ORN. Interestingly, PRP/PRF has been used in combination with autologous free fat graft [46], statins [47], and allogenic dental pulp stem cells [48] in the treatment of established ORN with promising results. However, most of the available data promoting the use of platelet concentrates in ORN are obtained from case-reports with relatively low-level of evidence [46-50]. 
The use of platelet concentrate as an adjunct in management of MRONJ was first described in 2007 by Adornato et al., where a combination of osseous resection, PRP, and a resorbable membrane was used to treat 12 patients with refractory MRONJ. Ten of the patients recovered with complete mucosal and bone healing [51]. Different forms of autologous platelet concentrates (APCs) have been described in the management of MRONJ, namely PRP, PRGF, and PRF [52-54].

Systematic review of the use of APC in the treatment and prevention of bisphosphonaterelated osteonecrosis of the jaw (BRONJ) conducted by Del Fabbro et al. in 2015 showed that the adjunct of APC may produce a significant benefit in the treatment BRONJ by reducing the recurrence of such conditions [52]. Results showed that satisfactory healing was observed in $91.6 \%$ of 143 patients with BRONJ treated with surgery and APC [52]. This was a superior outcome when compared to findings from another systematic review/literature review in which complete healing of the lesion was observed in $60.4 \%$ of a total of 124 patients treated with surgical treatment alone [55] and 85.98\% among 123 patients in eight studies using the PRP and L-PRF [30].

Recent studies on the use of L-PRF on MRONJ showed successful short-term results, i.e., mucosal integrity, absence of infection, and pain evaluation [56]; however, there was no statistically significant difference in terms of improvement between APC application and surgical treatment [57], and combination of antibiotic therapy, surgery, L-PRF, and photobiomodulation may contribute to MRONJ management [58]. In addition, recent reports on L-PRF and ORN showed good results on the healing [46,50].

Many of the above studies did not show high level of evidence to establish the effectiveness of autologous platelet concentrates (APC) in prevention and management of MRONJ, mainly due to the scarcity of randomized controlled trials, lack of multicentric studies, discrepancy in definition of treatment success, heterogenous drug administration, small sample sizes, and use of different treatment protocols among studies [30,52,57].

Although the current case series yielded satisfactory treatment outcomes, however, it is not without limitations. This study included a small sample size and as this is a retrospective analysis of the patient records, the treatment protocols lack uniformity. Subjects who are asymptomatic and/or at risks of developing ORN and MRONJ were excluded from this case series as we aimed to assess the treatment outcomes using the L-PRF. This series focused on cases who received L-PRF alone, and there was no control involved. The usefulness of the L-PRF addressed in this study was purely from clinical observation alone based on the outcome mentioned in Section 2.5.

In addition to its retrospective design nature, the other limitation of this case series is that it does not comply fully to the case series guidelines, for example, The Preferred Reporting of CasE Series in Surgery (PROCESS) guideline [59].

Future studies with larger sample of ORN and MRONJ patients (with cases and controls) using standardized treatment protocol are needed to validate the therapeutic efficacy of L-PRF.

\section{Conclusions}

Although the method used in the present study showed a high rate of success, it was applied in a limited number of patients, some of whom were followed up for a very short period of time. The true effectiveness of the method is yet to be demonstrated in a longer follow-up study including a greater number of patients, besides the inclusion of a control group.

Author Contributions: Conceptualization, R.R. and B.L.; Methodology, B.L. and H.Y.S.; writingoriginal draft preparation, B.L., H.Y.S.; writing-review and editing, B.L., H.Y.S., S.N., R.K.R. and A.J.N.; supervision, R.R.; project administration, R.R.; All authors have read and agreed to the published version of the manuscript.

Funding: This research received no external funding. 
Institutional Review Board Statement: The study was conducted according to the guidelines of the Declaration of Helsinki and approved by the Institutional Review Board (or Ethics Committee) of Universiti Kebangsaan Malaysia Research Ethics Committee (UKM PPI/111/8/JEP-2020-738).

Informed Consent Statement: Since the design of this study was a retrospective record review, an informed consent was not required except for permission for photography.

Data Availability Statement: Not applicable.

Conflicts of Interest: The authors declare no conflict of interest.

\begin{tabular}{|c|c|}
\hline MRONJ & medication-related osteonecrosis of the jaw \\
\hline ORN & osteoradionecrosis \\
\hline L-PRF & leucocyte and platelet-rich fibrin \\
\hline APC & autologous platelet concentrate \\
\hline AFA & autologous fibrin adhesive \\
\hline PRP & platelet-rich plasma \\
\hline PDGF & platelet-derived growth factor \\
\hline TGF- $\beta 1$ & transforming growth factor beta1 \\
\hline TGF- $\beta 2$ & transforming growth factor beta2 \\
\hline PDGF-AB & platelet-derived growth factor $\mathrm{AB}$ \\
\hline VEGF & vascular endothelial growth factor \\
\hline TSP-1 & thrombospondin-1 \\
\hline IGF-1 & insulin-like growth factor \\
\hline $\mathrm{HBO}$ & hyperbaric oxygen \\
\hline BRONJ & bisphosphonates-related osteonecrosis of the jaws \\
\hline AAOMS & American Association of Oral and Maxillofacial Surgeons \\
\hline RANKL & receptor activator for nuclear factor kappa-B ligand \\
\hline AFFG & autogenous free fat graft \\
\hline HSP47 & heatshockprotein 47 \\
\hline LOX & lysyl oxidase \\
\hline
\end{tabular}

\section{References}

1. Wepner, F.; Fries, R.; Platz, H. The Use of the Fibrin Adhesion System for Local Hemostasis in Oral Surgery. J. Oral Maxillofac. Surg. 1982, 40, 555-558. [CrossRef]

2. Tayapongsak, P.; O’Brien, D.A.; Monteiro, C.B.; Arceo-Diaz, L.Y. Autologous Fibrin Adhesive in Mandibular Reconstruction with Particulate Cancellous Bone and Marrow. J. Oral Maxillofac. Surg. 1994, 52, 161-165. [CrossRef]

3. Marx, R.E.; Carlson, E.R.; Eichstaedt, R.M.; Schimmele, S.R.; Strauss, J.E.; Georgeff, K.R. Platelet-Rich Plasma: Growth Factor Enhancement for Bone Grafts. Oral Surg. Oral Med. Oral Pathol. Oral Radiol. Endodontol. 1998, 85, 638-646. [CrossRef]

4. Schlegel, K.A.; Donath, K.; Rupprecht, S.; Falk, S.; Zimmermann, R. De Novo Bone Formation Using Bovine Collagen and Platelet-Rich Plasma. Biomaterials 2004, 25, 5387-5393. [CrossRef]

5. He, L.; Lin, Y.; Hu, X.; Zhang, Y.; Wu, H. A Comparative Study of Platelet-Rich Fibrin (PRF) and Platelet-Rich Plasma (PRP) on the Effect of Proliferation and Differentiation of Rat Osteoblasts in Vitro. Oral Surg. Oral Med. Oral Pathol. Oral Radiol. Endodontol. 2009, 108, 707-713. [CrossRef]

6. Thorwarth, M.; Rupprecht, S.; Falk, S.; Felszeghy, E.; Wiltfang, J.; Schlegel, K.A. Expression of Bone Matrix Proteins during de Novo Bone Formation Using a Bovine Collagen and Platelet-Rich Plasma (Prp)—An Immunohistochemical Analysis. Biomaterials 2005, 26, 2575-2584. [CrossRef]

7. Weibrich, G.; Kleis, W.K.; Hafner, G.; Hitzler, W.E.; Wagner, W. Comparison of Platelet, Leukocyte, and Growth Factor Levels in Point-of-Care Platelet-Enriched Plasma, Prepared Using a Modified Curasan Kit, with Preparations Received from a Local Blood Bank. Clin. Oral Implant. Res. 2003, 14, 357-362. [CrossRef]

8. Anitua, E. Plasma Rich in Growth Factors: Preliminary Results of Use in the Preparation of Future Sites for Implants. Int. J. Oral Maxillofac. Implant. 1999, 14, 529-535.

9. Weibrich, G.; Kleis, W.K.; Hitzler, W.E.; Hafner, G. Comparison of the Platelet Concentrate Collection System with the Plasma Rich-Ingrowth-Factors Kit to Produce Platelet-Rich Plasma: A Technical Report. Int. J. Oral Maxillofac. Implant. 2005, 20, 118-123.

10. Tamimi, F.M.; Montalvo, S.; Tresguerres, I.; Blanco Jerez, L. A Comparative Study of 2 Methods for Obtaining Platelet-Rich Plasma. J. Oral Maxillofac. Surg. 2007, 65, 1084-1093. [CrossRef]

11. Leitner, G.C.; Gruber, R.; Neumüller, J.; Wagner, A.; Kloimstein, P.; Höcker, P.; Körmöczi, G.F.; Buchta, C. Platelet Content and Growth Factor Release in Plateletrich Plasma: A Comparison of Four Different Systems. Vox Sang. 2006, 91, 135-139. [CrossRef] 
12. Choukroun, J.; Adda, F.; Schoeffer, C.; Vervelle, A. PRF: An Opportunity in Perio-Implantology. Implant. Dent. 2001, 42, 55-62. (In French)

13. Dohan Ehrenfest, D.M.; de Peppo, G.M.; Doglioli, P.; Sammartino, G. Slow Release of Growth Factors and Thrombospondin-1 in Choukroun's Platelet-Rich Fibrin (PRF): A Gold Standard to Achieve for All Surgical Platelet Concentrates Technologies. Growth Factors 2009, 27, 63-69. [CrossRef]

14. Polimeni, G.; Xiropaidis, A.V.; Wikesjö, U.M.E. Biology and Principles of Periodontal Wound Healing/Regeneration. Periodontol. 2000 2006, 41, 30-47. [CrossRef]

15. Graves, D.T.; Valentin-Opran, A.; Delgado, R.; Valente, A.J.; Mundy, G.; Piche, J. The Potential Role of Platelet-Derived Growth Factor as an Autocrine or Paracrine Factor for Human Bone Cells. Connect. Tissue Res. 1989, 23, 209-218. [CrossRef]

16. Maeda, S.; Hayashi, M.; Komiya, S.; Imamura, T.; Miyazono, K. Endogenous TGF-Beta Signaling Suppresses Maturation of Osteoblastic Mesenchymal Cells. EMBO J. 2004, 23, 552-563. [CrossRef]

17. Ferrara, N.; Gerber, H.; Lecouter, J. The Biology of VEGF and Its Receptors. Nat. Med. 2003, 9, 669-676. [CrossRef]

18. Lyons, A.; Ghazali, N. Osteoradionecrosis of the Jaws: Current Understanding of Its Pathophysiology and Treatment. Br. J. Oral Maxillofac. Surg. 2008, 46, 653-660. [CrossRef]

19. Nabil, S.; Samman, N. Risk Factors for Osteoradionecrosis after Head and Neck Radiation: A Systematic Review. Oral Surg. Oral Med. Oral Pathol. Oral Radiol. 2012, 113, 54-69. [CrossRef]

20. Delanian, S.; Lefaix, J.-L. The Radiation-Induced Fibroatrophic Process: Therapeutic Perspective via the Antioxidant Pathway. Radiother. Oncol. 2004, 73, 119-131. [CrossRef]

21. Marx, R.E. Pamidronate (Aredia) and Zoledronate (Zometa) Induced Avascular Necrosis of the Jaws: A Growing Epidemic. J. Oral Maxillofac. Surg. 2003, 61, 1115-1117. [CrossRef]

22. Ruggiero, S.L.; Dodson, T.B.; Fantasia, J.; Goodday, R.; Aghaloo, T.; Mehrotra, B.; O’Ryan, F. American Association of Oral and Maxillofacial Surgeons Position Paper on Medication-Related Osteonecrosis of the Jaw-2014 Update. J. Oral Maxillofac. Surg. 2014, 72, 1938-1956. [CrossRef] [PubMed]

23. Saad, F.; Brown, J.E.; Van Poznak, C.; Ibrahim, T.; Stemmer, S.M.; Stopeck, A.T.; Diel, I.J.; Takahashi, S.; Shore, N.; Henry, D.H.; et al. Incidence, Risk Factors, and Outcomes of Osteonecrosis of the Jaw: Integrated Analysis from Three Blinded Active-Controlled Phase III Trials in Cancer Patients with Bone Metastases. Ann. Oncol. 2012, 23, 1341-1347. [CrossRef] [PubMed]

24. Guarneri, V.; Miles, D.; Robert, N.; Diéras, V.; Glaspy, J.; Smith, I.; Thomssen, C.; Biganzoli, L.; Taran, T.; Conte, P. Bevacizumab and Osteonecrosis of the Jaw: Incidence and Association with Bisphosphonate Therapy in Three Large Prospective Trials in Advanced Breast Cancer. Breast Cancer Res. Treat. 2010, 122, 181-188. [CrossRef]

25. Christodoulou, C.; Pervena, A.; Klouvas, G.; Galani, E.; Falagas, M.E.; Tsakalos, G.; Visvikis, A.; Nikolakopoulou, A.; Acholos, V.; Karapanagiotidis, G.; et al. Combination of Bisphosphonates and Antiangiogenic Factors Induces Osteonecrosis of the Jaw More Frequently than Bisphosphonates Alone. Oncology 2009, 76, 209-211. [CrossRef]

26. Aragon-Ching, J.B.; Ning, Y.M.; Chen, C.C.; Latham, L.; Guadagnini, J.P.; Gulley, J.L.; Arlen, P.M.; Wright, J.J.; Parnes, H.; Figg, W.D.; et al. Higher Incidence of Osteonecrosis of the Jaw (ONJ) in Patients with Metastatic Castration Resistant Prostate Cancer Treated with Anti-Angiogenic Agents. Cancer Investig. 2009, 27, 221-226. [CrossRef]

27. Chang, J.; Hakam, A.E.; McCauley, L.K. Current Understanding of the Pathophysiology of Osteonecrosis of the Jaw. Curr. Osteoporos. Rep. 2018, 16, 584-595. [CrossRef]

28. Aghaloo, T.; Hazboun, R.; Tetradis, S. Pathophysiology of Osteonecrosis of the Jaws. Oral Maxillofac. Surg. Clin. N. Am. 2015, 27, 489-496. [CrossRef]

29. Allegra, A.; Innao, V.; Pulvirenti, N.; Musolino, C. Antiresorptive Agents and Anti-Angiogenesis Drugs in the Development of Osteonecrosis of the Jaw. Tohoku J. Exp. Med. 2019, 248, 27-29. [CrossRef]

30. Lopez-Jornet, P.; Sanchez Perez, A.; Amaral Mendes, R.; Tobias, A. Medication-Related Osteonecrosis of the Jaw: Is Autologous Platelet Concentrate Application Effective for Prevention and Treatment? A Systematic Review. J. Cranio Maxillofac. Surg. 2016, 44, 1067-1072. [CrossRef]

31. Epstein, M.S.; Wicknick, F.W.; Epstein, J.B.; Berenson, J.R.; Gorsky, M. Management of Bisphosphonate-Associated Osteonecrosis: Pentoxifylline and Tocopherol in Addition to Antimicrobial Therapy. An Initial Case Series. Oral Surg. Oral Med. Oral Pathol. Oral Radiol. Endodontol. 2010, 110, 593-596. [CrossRef]

32. Freiberger, J.J.; Padilla-Burgos, R.; Chhoeu, A.H.; Kraft, K.H.; Boneta, O.; Moon, R.E.; Piantadosi, C.A. Hyperbaric Oxygen Treatment and Bisphosphonate-Induced Osteonecrosis of the Jaw: A Case Series. J. Oral Maxillofac. Surg. 2007, 65, 1321-1327. [CrossRef]

33. Notani, K.I.; Yamazaki, Y.; Kitada, H.; Sakakibara, N.; Fukuda, H.; Omori, K.; Nakamura, M. Management of Mandibular Osteoradionecrosis Corresponding to the Severity of Osteoradionecrosis and the Method of Radiotherapy. Head Neck J. Sci. Spec. Head Neck 2003, 25, 181-186. [CrossRef]

34. Dohan, D.M.; Choukroun, J.; Diss, A.; Dohan, S.L.; Dohan, A.J.J.; Mouhyi, J.; Gogly, B. Platelet-Rich Fibrin (PRF): A SecondGeneration Platelet Concentrate. Part II: Platelet-Related Biologic Features. Oral Surg. Oral Med. Oral Pathol. Oral Radiol. Endodontol. 2006, 101, e45-e50. [CrossRef]

35. Dohan, D.M.; Choukroun, J.; Diss, A.; Dohan, S.L.; Dohan, A.J.J.; Mouhyi, J.; Gogly, B. Platelet-Rich Fibrin (PRF): A SecondGeneration Platelet Concentrate. Part III: Leucocyte Activation: A New Feature for Platelet Concentrates? Oral Surg. Oral Med. Oral Pathol. Oral Radiol. Endodontol. 2006, 101, e51-e55. [CrossRef] 
36. Dohan Ehrenfest, D.M.; Diss, A.; Odin, G.; Doglioli, P.; Hippolyte, M.P.; Charrier, J.B. In Vitro Effects of Choukroun's PRF (Platelet-Rich Fibrin) on Human Gingival Fibroblasts, Dermal Prekeratinocytes, Preadipocytes, and Maxillofacial Osteoblasts in Primary Cultures. Oral Surg. Oral Med. Oral Pathol. Oral Radiol. Endodontol. 2009, 108, 341-352. [CrossRef]

37. Dohan Ehrenfest, D.M.; Doglioli, P.; de Peppo, G.M.; Del Corso, M.; Charrier, J.B. Choukroun's Platelet-Rich Fibrin (PRF) Stimulates in Vitro Proliferation and Differentiation of Human Oral Bone Mesenchymal Stem Cell in a Dose-Dependent Way. Arch. Oral Biol. 2010, 55, 185-194. [CrossRef]

38. Dohan Ehrenfest, D.M.; Bielecki, T.; Jimbo, R.; Barbe, G.; Del Corso, M.; Inchingolo, F.; Sammartino, G. Do the Fibrin Architecture and Leukocyte Content Influence the Growth Factor Release of Platelet Concentrates? An Evidence-Based Answer Comparing a Pure Platelet-Rich Plasma (P-PRP) Gel and a Leukocyte- and Platelet-Rich Fibrin (L-PRF). Curr. Pharm. Biotechnol. 2012, 13, 1145-1152. [CrossRef]

39. Van den Dolder, J.; Mooren, R.; Vloon, A.P.G.; Stoelinga, P.J.W.; Jansen, J.A. Platelet-Rich Plasma: Quantification of Growth Factor Levels and the Effect on Growth and Differentiation of Rat Bone Marrow Cells. Tissue Eng. 2006, 12, 3067-3073. [CrossRef]

40. Roy, S.; Driggs, J.; Elgharably, H.; Biswas, S.; Findley, M.; Khanna, S.; Gnyawali, U.; Bergdall, V.K.; Sen, C.K. Platelet-Rich Fibrin Matrix Improves Wound Angiogenesis via Inducing Endothelial Cell Proliferation. Wound Repair Regen. 2011, 19, 753-766. [CrossRef]

41. Sinder, B.P.; Pettit, A.R.; McCauley, L.K. Macrophages: Their Emerging Roles in Bone. J. Bone Miner. Res. 2015, 30, $2140-2149$. [CrossRef] [PubMed]

42. Wu, C.-L.; Lee, S.-S.; Tsai, C.-H.; Lu, K.-H.; Zhao, J.-H.; Chang, Y.-C. Platelet-Rich Fibrin Increases Cell Attachment, Proliferation and Collagen-Related Protein Expression of Human Osteoblasts. Aust. Dent. J. 2012, 57, 207-212. [CrossRef] [PubMed]

43. Tsay, R.C.; Vo, J.; Burke, A.; Eisig, S.B.; Lu, H.H.; Landesberg, R. Differential Growth Factor Retention by Platelet-Rich Plasma Composites. J. Oral Maxillofac. Surg. 2005, 63, 521-528. [CrossRef] [PubMed]

44. Scala, M.; Gipponi, M.; Mereu, P.; Strada, P.; Corvò, R.; Muraglia, A.; Massa, M.; Bertoglio, S.; Santi, P.; Cafiero, F. Regeneration of Mandibular Osteoradionecrosis Defect with Platelet Rich Plasma Gel. In Vivo 2010, 24, 889-893. [PubMed]

45. Batstone, M.D.; Cosson, J.; Marquart, L.; Acton, C. Platelet Rich Plasma for the Prevention of Osteoradionecrosis. A Double Blinded Randomized Cross Over Controlled Trial. Int. J. Oral Maxillofac. Surg. 2012, 41, 2-4. [CrossRef]

46. Law, B.; Yunus, S.S.M.; Ramli, R. Autogenous Free Fat Graft Combined with Platelet-Rich Fibrin Heals a Refractory Mandibular Osteoradionecrosis. Clin. Ter. 2020, 171, E110-E113.

47. Baliga, M.; Chakraborty, S.; Kumari, T.; Tusharbhai, D.M.; Sarkar, S. Is There a Role for PRF with Simvastatin in Stage I Osteoradionecrosis? Oral Oncol. 2018, 87, 177-178. [CrossRef]

48. Manimaran, K.; Sankaranarayanan, S.; Ravi, V.R.; Elangovan, S.; Chandramohan, M.; Perumal, S.M. Treatment of Osteoradionecrosis of Mandible with Bone Marrow Concentrate and with Dental Pulp Stem Cells. Ann. Maxillofac. Surg. 2014, 4, 189-192.

49. Maluf, G.; Caldas, R.J.; Fregnani, E.R.; da Silva Santos, P.S. Leukocyte- and Platelet-Rich Fibrin as an Adjuvant to the Surgical Approach for Osteoradionecrosis: A Case Report. J. Korean Assoc. Oral Maxillofac. Surg. 2020, 46, 150-154. [CrossRef]

50. Chen, Y.-T.; Chang, Y.-C. Use of Platelet-Rich Fibrin and Surgical Approach for Combined Treatment of Osteoradionecrosis: A Case Report. J. Int. Med. Res. 2019, 47, 3998-4003. [CrossRef]

51. Adornato, M.C.; Morcos, I.; Rozanski, J. The Treatment of Bisphosphonate associated Osteonecrosis of the Jaws with Bone Resection and Autologous Platelet-Derived Growth Factors. J. Am. Dent. Assoc. 2007, 138, 971-977. [CrossRef]

52. Del Fabbro, M.; Gallesio, G.; Mozzati, M. Autologous Platelet Concentrates for Bisphosphonate-Related Osteonecrosis of the Jaw Treatment and Prevention. A Systematic Review of the Literature. Eur. J. Cancer 2015, 51, 62-74. [CrossRef]

53. Kim, J.W.; Kim, S.J.; Kim, M.R. Leucocyte-Rich and Platelet-Rich Fibrin for the Treatment of Bisphosphonate-Related Osteonecrosis of the Jaw: A Prospective Feasibility Study. Br. J. Oral Maxillofac. Surg. 2014, 52, 854-859. [CrossRef]

54. Bocanegra-Pérez, S.; Vicente-Barrero, M.; Knezevic, M.; Castellano-Navarro, J.M.; Rodríguez-Bocanegra, E.; Rodríguez-Millares, J.; Pérez-Plasencia, D.; Ramos-Macías, A. Use of Platelet-Rich Plasma in the Treatment of Bisphosphonate-Related Osteonecrosis of the Jaw. Int. J. Oral Maxillofac. Surg. 2012, 41, 1410-1415. [CrossRef]

55. Kühl, S.; Walter, C.; Acham, S.; Pfeffer, R.; Lambrecht, J.T. Bisphosphonate-Related Osteonecrosis of the Jaws-A Review. Oral Oncol. 2012, 48, 938-947. [CrossRef]

56. Giudice, A.; Barone, S.; Giudice, C.; Bennardo, F.; Fortunato, L. Can Platelet-Rich Fibrin Improve Healing after Surgical Treatment of Medication-Related Osteonecrosis of the Jaw? A Pilot Study. Oral Surg. Oral Med. Oral Pathol. Oral Radiol. Endodontol. 2018, 126, 390-403. [CrossRef]

57. Fortunato, L.; Bennardo, F.; Buffone, C.; Giudice, A. Is the Application of Platelet Concentrates Effective in the Prevention and Treatment of Medication-Related Osteonecrosis of the Jaw? A Systematic Review. J. Cranio Maxillofac. Surg. 2020, 48, 268-285. [CrossRef]

58. Tenore, G.; Zimbalatti, A.; Rocchetti, F.; Graniero, F.; Gaglioti, D.; Mohsen, A.; Caputo, M.; Lollobrigida, M.; Lamazza, L.; De Biase, A.; et al. Management of Medication-Related Osteonecrosis of the Jaw (MRONJ) Using Leukocyte- and Platelet-Rich Fibrin (L-PRF) and Photobiomodulation: A Retrospective Study. J. Clin. Med. 2020, 9, 3505. [CrossRef]

59. Agha, R.A.; Fowler, A.J.; Rajmohan, S.; Barai, I.; Orgill, D.P.; PROCESS Group. Preferred reporting of case series in surgery; The PROCESS guidelines. Int. J. Surg. 2016, 36 Pt A, 319-323. [CrossRef] 